\title{
Fullerenes in Electrochemical Catalytic and Affinity Biosensing: A Review
}

\author{
Paloma Yáñez-Sedeño ${ }^{1}$, Susana Campuzano ${ }^{1, *}$ and José M. Pingarrón ${ }^{1,2, *}$ \\ 1 Departamento de Química Analítica, Facultad de CC. Químicas, Universidad Complutense de Madrid, \\ E-28040 Madrid, Spain; yseo@quim.ucm.es \\ 2 IMDEA Nanoscience, Ciudad Universitaria de Cantoblanco, 28049 Madrid, Spain \\ * Correspondence: susanacr@quim.ucm.es (S.C.); pingarro@quim.ucm.es (J.M.P.); \\ Tel.: +34-91-394-4368 (S.C.); +34-91-394-4315 (J.M.P.); Fax: +34-91-394-4329 (S.C. \& J.M.P.)
}

Received: 13 June 2017; Accepted: 26 June 2017; Published: 28 June 2017

\begin{abstract}
Nanotechnology is becoming increasingly important in the field of (bio)sensors. The performance and sensitivity of electrochemical biosensors can be greatly improved by the integration of nanomaterials into their construction. In this sense, carbon nanomaterials have been widely used for preparation of biosensors due to their ability to enhance electron-transfer kinetics, high surface-to-volume ratios, and biocompatibility. Fullerenes are a very promising family of carbon nanomaterials and have attracted great interest in recent years in the design of novel biosensing systems due to fullerenes' exceptional properties. These include multiple redox states, stability in many redox forms, easy functionalization and signal mediation. This paper outlines the state-of-the-art and future directions in the use and functionalization of fullerene- $\mathrm{C}_{60}$ and its derivatives, both as electrode modifiers and advanced labels in electrochemical catalytic and affinity biosensors through selected applications.
\end{abstract}

Keywords: fullerene; electrochemical biosensor; catalytic biosensor; affinity biosensor; electrode modifiers; nanocarriers

\section{Introduction}

The current demands for reliable electrochemical biosensing require the development of sensing (bio)platforms exhibiting large surface area to allow for the high loading of capture molecules, good biocompatibility for biological activity preservation, and excellent conductivity for electron transportation [1].

In this context, carbon nanomaterials have attracted great interest because of the structural differences in their various allotropes (e.g., graphite, fullerene, carbon nanotubes (CNT), graphene, diamond, diamond-like carbon (DLC)) (see Figure 1) and their wide variety of structurally dependent electronic and electrochemical properties [2]. Carbon nanomaterials cover a broad range of structures: zero-dimensional (fullerenes, diamond clusters), one-dimensional (nanotubes), two-dimensional (graphene), and three-dimensional (nanocrystalline diamond, fullerite) structures [3]. Carbon nanomaterials such as multiwalled carbon nanotubes (MWCNTs) and fullerene $\left(\mathrm{C}_{60}\right)$ offer great versatility in terms of facile modification by functional groups, high carrier capacity incorporating both hydrophilic and hydrophobic substances, biocompatibility, relatively wide potential window, low background current, electrocatalytic capability for a variety of redox reactions, and high chemical stability [3,4]. This has led to their wide use in recent years for the preparation of electrochemical (bio)sensors, both as electrode modifiers and nanocarriers. 
(a)

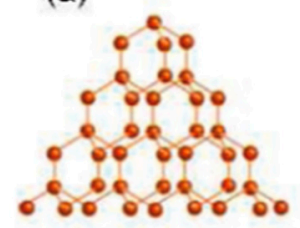

(c)

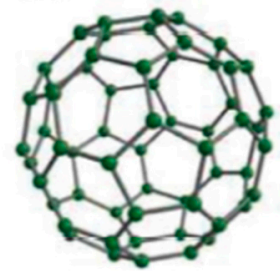

(b)

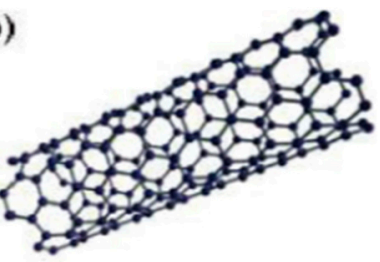

(d)

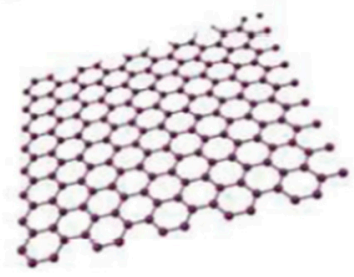

Figure 1. Main carbon nanomaterials used in electrochemical (bio)sensors classified by the type of carbon bond and structure: $\mathrm{sp}^{3}$-bonded diamond (a) and $\mathrm{sp}^{2}$-bonded carbon (b-d); carbon nanotubes (CNT) (1D-structure) (b); fullerene (0D-structure) (c); and, graphene (2D-structure) (d). Reprinted from [2] with permission.

Due to their special physicochemical characteristics, fullerenes add a new dimension to the construction of highly sensitive electrochemical biosensors. Fullerenes are a very promising family of electroactive compounds with a rich electrochemistry because of the unique dimensional and electronic structure [5] that makes them very attractive as mediators in electrochemical biosensors, allowing operation at lower potentials, thus reducing the interferences from electroactive compounds [6].

\section{Fullerenes in Electrochemical Biosensing}

Fullerene $\left(\mathrm{C}_{60}\right)$, as a zero-dimensional carbon, is the most abundant representative of the fullerene family [7]. $\mathrm{C}_{60}$ is a truncated icosahedron made out of five and six member rings of $\mathrm{sp}^{2}$ carbons, which plays an important role in the family of nanocarbons [8]. $\mathrm{C}_{60}$ has a broad range of charming properties, such as high electronic conductivity, large specific surface area, good biocompatibility, inert behavior, stable structure and good adsorption capacity towards organic molecules [9-11]. Moreover, it is free of metallic impurities and relatively simple to implement and raise to reproducible electrocatalytic responses [12].

Despite the wide range of interesting characteristics and properties in terms of electrical conductivity and charge transport, pure $\mathrm{C}_{60}$ has been scarcely used as a possible electrode material. However, this hollow carbon sphere, rich in conjugated $\pi$ electrons with excellent electron acceptor capability to accelerate electron transfer $[1,8,13]$, can react with amines [14] and be successfully decorated with other materials [6,12,15-17]. This explains the increasing interest in the preparation of $\mathrm{C}_{60}$ composites with other nanomaterials to achieve new physical and chemical properties especially relevant for the application of $\mathrm{C}_{60}$ in novel electrode materials and the fabrication of sensors and biosensors [18]. Indeed, the combination of $\mathrm{C}_{60}$ with nanomaterials such as nitrogen-doped carbon nanotubes (NCNTs) [18], AuNPs [1,6,15,19], and Pt-Pd nanoparticles [17] has been shown to be advantageous either because combining the unique properties of these two kinds of materials or the emergence of new properties leads to novel applications [12]. Moreover, $\mathrm{C}_{60}$ owned its inner redox activity [15], being able to act as an electron acceptor with a dual nature of electrophilic and nucleophilic characteristics, which has led to significant interest from researchers to investigate the possibilities of using this material as a mediator in biosensing devices $[4,15,20]$. Fullerene is used as a mediator between the recognition site and the electrode in electrochemical biosensors to enhance the rate of electron transfer produced due to the biocatalytic or biochemical reaction of the analyte in contact with the biological element at the recognition site (see Figure 2) [21]. Due to the ability of lowering the potential of electro-reduction of many different redox substrates and increasing the 
reaction rates, fullerenes have been used to improve the sensitivity and selectivity of the resulting biosensors [8]. Indeed, partially reduced fullerene- $\mathrm{C}_{60}$-modified electrodes have been demonstrated to behave as excellent working electrodes with a high electroactive surface area, excellent electronic conductivity, electrocatalytic properties and good biocompatibility [22-24]. However, it is worth noting here that the enhanced electrocatalytic behavior observed at the reduced $\mathrm{C}_{60}$-modified electrodes has been a controversial matter addressed by several authors. While some works support that $\mathrm{C}_{60}$ is involved in effective electron mediation or electrocatalysis [25], others did not find any experimental evidence of the electrocatalytic ability of $C_{60}$ when it was used as electrodes modifier [26-28], This "apparent electrocatalytic behavior" was attributed to a re-structuration of the deposited $\mathrm{C}_{60}$ film, which produces a porous, partially blocked electrode, and possible thin-layer effects $[29,30]$.

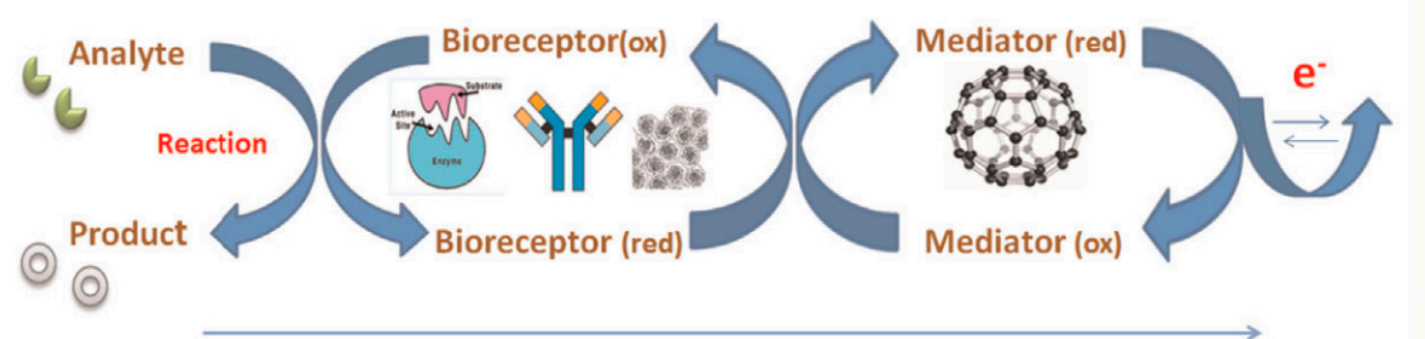

Biochemical signal to electrical signal: role of fullerene (functionalized)

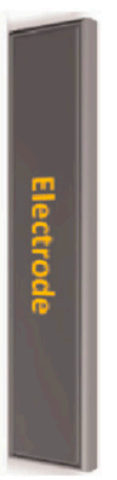

Figure 2. Schematic display of fullerene function as a redox mediator in an electrochemical biosensor. Reprinted from [21] with permission.

Moreover, $\mathrm{C}_{60}$ and their derivatives such as pristine $\mathrm{C}_{60}$ nanoparticles are aggregated in aqueous medium and their redox activity is inhibited because of their poor solubility in water. This makes the electrochemical behavior of $\mathrm{C}_{60}$-based nanomaterials in aqueous media unstable and irreversible. This problem can be overcome by $\mathrm{C}_{60}$ functionalization though the covalent binding of functional groups such as carboxyl, hydroxyl, amine groups, etc. [4,7,19,21]. For example, hydroxyl fullerenes $(\mathrm{HFs})$ are water soluble fullerene derivatives with a formula of $\mathrm{C}_{60}(\mathrm{OH})_{n}(n=18-24)$. HFs may link with a protein to form specific noncovalent complexes and protect their biological activity. They are also useful for the formation of gels, starburst polymers and composites [31].

On the other hand, the synthesis of functionalized $C_{60}$ or their derivatives through non-covalent interactions involving supramolecular chemistry has shown to preserve the original structure and electrochemical properties of $\mathrm{C}_{60}$ [4].

The incorporation of fullerenes for preparing electrochemical biosensors has led to the development of a variety of fullerene functionalization methods, profiting the high surface area-to-volume ratio of these nanomaterials. Amine and carboxylic acid functional groups have been widely incorporated into fullerenes to allow them to easily react with biomolecules [21]. From the viewpoint of fullerene chemistry, functionalized fullerene can be categorized into two basic types: exohedral, where substituents are intercalated outside the cage, and endohedral, where molecules are trapped inside the cage. It has been shown that exohedrally functionalized fullerenes bearing organic or organometallic functional groups attached to the exterior of the carbon cage are more accessible than endohedral metallofullerenes. Numerous research efforts support the notion that exohedral functionalized fullerene can be a suitable nanomaterial able to improve the sensitivity, selectivity, and reproducibility of electrochemical biosensors [21]. Different biomolecules or organic ligands can be immobilized onto the shell of fullerenes by adsorption or covalent attachment. Since fullerenes are not harmful to biological material and due to their small size, they can locate the closest distance to the active site of biomolecules and easily accept or donate electrons to the surrounding species [4]. Electron-releasing molecules such as amines can attack fullerene- $\mathrm{C}_{60}$ with $60 \pi$ 
electrons. Therefore, biomolecules bearing $\mathrm{NH}$ groups are expected to bond chemically to the fullerene $\mathrm{C}_{60}$ molecule, resulting in the formation of stable immobilized $\mathrm{C}_{60}$-biomolecule conjugates $[4,32]$. Indeed, the functionalization of fullerene to prepare water-soluble derivatives and conjugates with enzymes (urease, glucose oxidase), proteins (hemoglobin, myoglobin), other biomolecules such as chitosan (CS), metals (e.g., $\mathrm{Au}$ ), ferrocene ( $\mathrm{Fc}$ ), and so forth, has proved to be successfully implemented for the preparation of biosensors. This improved the sensitivity towards glucose, urea, hemoglobin, immunoglobulin, or glutathione in real samples, as well as identifying doping abuse, to analyze pharmaceutical preparations, and even to detect tumor cells after the inclusion of fullerenes in single or double walled carbon nanotubes $[4,20,21]$.

The next sections discuss briefly the main advantages offered by fullerenes and their derivatives, such as fullerene- $\mathrm{C}_{60}$ nanoparticles and nanotubes (FNTs) [24] in electrochemical biosensing. In addition, we overview the main strategies reported for fullerene functionalization and significant and illustrative applications in the preparation of different types of electrochemical biosensors ranging from catalytic to affinity biosensors, when the nanomaterials are used as electrode modifiers, nanocarriers, and redox nanoprobes.

\section{Fullerenes in Catalytic Biosensing}

The preparation of effective third-generation enzyme biosensors implies the achievement of an efficient electron transport between redox centers of proteins and electrodes. However, it is well known that achieving direct electron transfer (DET) between the redox proteins and the electrode surface is challenging because the electroactive centers of proteins usually have large and complex structures, and the active sites are buried deeply in the molecule structures [33]. In addition, redox proteins absorbed on the electrode surface are easily irreversibly denatured [18].

The incorporation of nanomaterials to the biosensor architecture constitutes one of the most successful approaches to overcome these challenges and develop the next generation of biosensors or nanodevices with excellent electrochemical properties $[18,33]$. The electronic, optical, and catalytic properties of many nanomaterials and their dimensions similar to those of several biomolecules provide a suitable microenvironment for proteins immobilization, maintaining their bioactivity, and at the same time facilitating electron transfer between their redox center and electrode surfaces, which have led to their intensive use for the construction of electrochemical biosensors with enhanced analytical performance. The generated hybrid systems combine the unique electronic properties of nanomaterials with the recognition and catalytic function of biomolecules, thus allowing electrically wiring redox enzymes with electrodes and reducing electron transfer distances [6].

In the case of fullerenes, it has been shown they also provide a suitable microenvironment for the protein immobilization [4]. Additionally, they are small enough to locate at the closest distance of the active site of the enzyme and induce the protein molecule mobility to correctly orient the redox centers to achieve a proper electron transfer. Furthermore, as commented above, they are not harmful to biological material and proteins, and can interact with enzymes through several types of immobilization strategies (entrapment, encapsulation, covalent binding, cross-linking, and adsorption) involving covalent or non-covalent bonds [4].

Csiszár et al. demonstrated that the electrochemistry of immobilized cyt $\mathrm{c}$ depended strongly on the oxidation state and porosity of the fullerene films [34]. It was shown that better redox reaction was accomplished on partially reduced fullerene film, which acted as a promoter, independently of the underlying electrode substrate (gold or glassy carbon). Partially reduced fullerene possesses a structure with a polar or negatively charged outside and an apolar inside which resembles biomembranes, and raised the possibility of using fullerenes as solid state modifiers to enhance the electrochemistry and stability of immobilized biomolecules compared to bare electrodes. D'Souza et al. [35] reported the stable immobilization of cyt c on two types of fullerene film modified electrodes: one involving an electrochemically-conditioned fullerene drop-coated film and, another, an electro-polymerized fullerene-cross-linked with palladium acetate complex $\left(\mathrm{C}_{60}-\mathrm{Pd}\right)$ film (see Figure 3). More effective 
cyt $\mathrm{c}$ immobilization and DET was observed at the $\mathrm{C}_{60}-\mathrm{Pd}$ polymer film-modified electrodes. Immobilization of cyt $\mathrm{c}$ onto the $\mathrm{C}_{60}-\mathrm{Pd}$ polymer film-modified electrode was claimed to proceed via one or more of the following routes: (i) the electron-deficient $\mathrm{C}_{60}$ molecules may allow the electrostatically binding to the cyt $\mathrm{c}$ molecules through their electron-rich aspartic-glutamic acid residue sites; (ii) the negative charges stored in the $\mathrm{C}_{60}$ film may strongly adsorb electrostatically, via ion pairing, positively charged parts of the cyt c protein; (iii) the cyt $\mathrm{c}$ molecules may be trapped in the porous structure of the $\mathrm{C}_{60}$ or $\mathrm{C}_{60}-\mathrm{Pd}$ films.

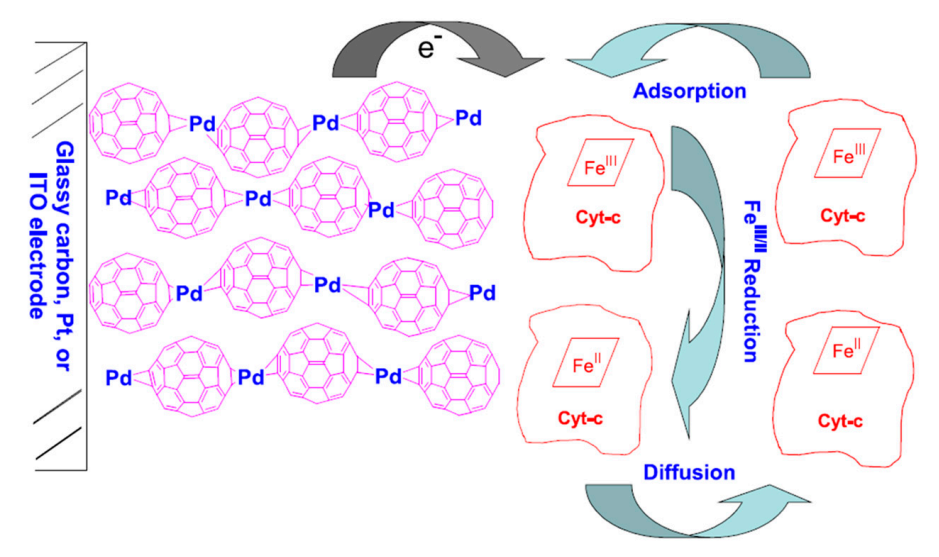

Figure 3. Schematic display showing the mechanism proposed for cyt $\mathrm{c}$ immobilization onto the $\mathrm{C}_{60}-\mathrm{Pd}$ polymer film-modified electrode and of cyt c electrochemical reduction. Reprinted from [35] with permission.

Zhilei et al. [13] developed an interesting third-generation glucose biosensor by the subsequent deposition of $\mathrm{C}_{60}$, ferrocene ( $\mathrm{Fc}$ ), chitosan (CS) ionic liquid (IL) and glucose oxidase (GOx) onto a glassy carbon electrode (GCE). By using chronoamperometry at $+100 \mathrm{mV}$ (vs. $\mathrm{Ag} / \mathrm{AgCl}$ ) the GOx $/ \mathrm{C}_{60}-\mathrm{Fc}-\mathrm{CS}-\mathrm{IL}$ biosensor exhibited DET, a wide calibration range $\left(1 \times 10^{-8}-1 \times 10^{-5} \mathrm{M}\right)$, an excellent limit of detection (LOD) of $3 \times 10^{-9} \mathrm{M}$ and long-term stability of 30 weeks due to the favorable microenvironment provided by the CS-IL network. This biosensor demonstrated accurate determination of glucose in blood serum samples. The excellent performance of this biosensor was attributed both to the electrocatalytic activity of $\mathrm{C}_{60}$ and $\mathrm{Fc}$, which accelerate the electrochemical reaction, and to the network of CS-IL, which provided a favorable microenvironment to keep the enzyme bioactivity, and the electron conduction pathways for GOx through $\mathrm{Fc}$ and $\mathrm{C}_{60}$.

Another glucose electrochemical biosensor was reported by Lin et al., involving the synthesis of a fullerene $\mathrm{C}_{60}$-glucose oxidase conjugate $\left(\mathrm{C}_{60}-\mathrm{GOx}\right)$ and its electrodeposition on a GCE previously modified with a mixed-valence cluster of cobalt(II) hexacyanoferrate [32]. The $\mathrm{C}_{60}-\mathrm{GOx} /$ cobalt(II) hexacyanoferrate-modified electrode exhibited efficient electrocatalytic activity toward the liberated $\mathrm{H}_{2} \mathrm{O}_{2}$ and allowed cathodic detection of glucose at $0.0 \mathrm{mV}$ (vs. $\mathrm{Ag} / \mathrm{AgCl}$ reference electrode). This biosensor showed a long life ( $\geq 100$ days), could be repeatedly reused for a long time, showed good selectivity, linear response up to $8 \mathrm{mM}$ glucose, and a LOD of $1.6 \times 10^{-6} \mathrm{M}$. Interestingly in this biosensor the presence of ascorbic acid almost did not affect the response obtained for glucose.

Sheng et al. [18] achieved direct electrochemistry of hemoglobin $(\mathrm{Hb})$ immobilized by a fullerene- $\mathrm{C}_{60}-\mathrm{NCNTs} /$ chitosan composite matrix. The $\mathrm{C}_{60}$ filled within NCNT could electronically dope the NCNT, then acting as electron mediator to facilitate the electrochemical reaction of the protein and achieving the fast electron transfer between $\mathrm{Hb}$ and the electrode surface. It was suggested that the $\mathrm{C}_{60}-\mathrm{NCNTs} / \mathrm{CHIT}$ composite film may mimic some physiological process. Moreover, this electrochemical platform catalyzed the reduction of $\mathrm{H}_{2} \mathrm{O}_{2}$, kept $95 \%$ of the initial sensitivity after 2 months of storage, and provided a wide linearity range $(2.0-225.0 \mu \mathrm{M})$ and a low LOD $(1 \mu \mathrm{M})$. 
This approach can be easily extended to other redox enzymes or proteins and find application for the design of biofuel cells and for the determination of $\mathrm{H}_{2} \mathrm{O}_{2}$ in biological and pharmaceutical samples.

Saeedfar et al. [9] developed a potentiometric urea biosensor based on the use of a $\mathrm{C}_{60}$-urease bioconjugate prepared by covalent immobilization of urease onto $\mathrm{COOH}$-modified $\mathrm{C}_{60}$ deposited on a screen-printed electrode (SPE) coated with a good adhesion acrylic membrane entrapping a hydrogen ionophore. The biosensor exhibited a linear response from $2.31 \times 10^{-3}$ to $8.28 \times 10^{-5} \mathrm{M}$ urea and a stability of up to 140 days. This great stability was attributed to the prevented leaching of the enzyme by the acrylic membrane.

Gao et al. [31] developed a sensitive and selective glucose biosensor showing the direct electrochemistry of GOx by immobilizing GOx-HFs nano-complexes on a GCE protected with a chitosan (Chit) membrane. Amperometric detection at $-0.35 \mathrm{~V}$ (vs. $\mathrm{Ag} / \mathrm{AgCl}$ ) provided a response for glucose ranging from 0.05 to $30 \mathrm{mM}$ (with $0.05-1.0 \mathrm{mM}$ and 3-10 $\mathrm{mM}$ ) and provided a LOD of $5 \pm 1 \mu \mathrm{M}$. The presented results demonstrated that Chit/HFs preserved the conformational structure of the enzyme providing the resultant biosensor with high sensitivity and selectivity.

A nanostructured laccase biosensor was developed by Lanzellotto et al. [6] by exploiting the beneficial features of poly hydroxy-fullerenes (fullerenols) and AuNPs (see Figure 4a). The biosensor construction involved the immobilization of functionalized AuNPs on an Au/SPE modified with a cysteamine self-assembled monolayer. Subsequently, fullerenols were linked onto the AuNP-modified electrode and the Trametes versicolor laccase enzyme $(\mathrm{TvL})$ was immobilized. Using gallic acid as standard, and chronoamperometric detection $\left(\mathrm{E}_{\mathrm{app}}=-0.100 \mathrm{~V}\right.$ vs. $\left.\mathrm{Ag} / \mathrm{AgCl}\right)$, the biosensor exhibited DET, a linear range from 0.03 to $0.30 \mathrm{mM}$, an LOD of $0.006 \mathrm{mM}$, and provided reliable results in the analysis of commercial wines (Figure 4b). Recently Tortolini et al. [33] used this laccase biosensor as an amperometric detector in a flow injection analysis method for the determination of polyphenols in wine samples. These biosensing platforms, based on the coupling of two different nanostructured materials (gold nanoparticles and fullerenols), displayed interesting electrochemical features in terms of good stability and reproducibility, an increased amount of electroactive protein immobilized and enhanced electron transfer between the redox center of the protein and the electrode surface.

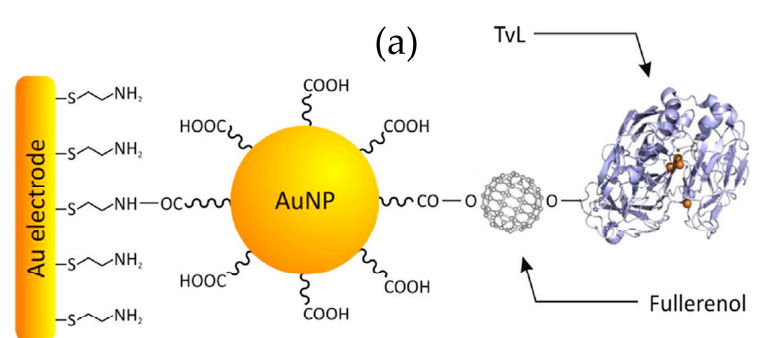

(b)

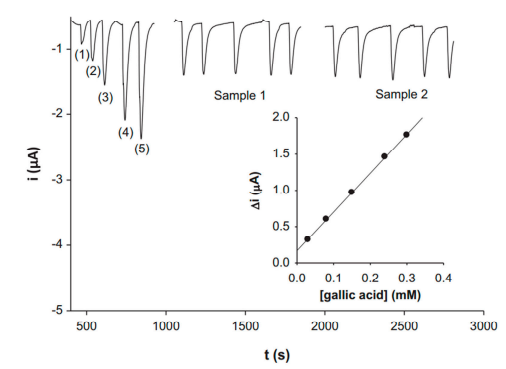

Figure 4. Au-SAM/AuNPs-linker/fullerenol/Trametes versicolor laccase enzyme (TvL) amperometric biosensor for the determination of polyphenols (a). Chronoamperometric responses recorded at $-100 \mathrm{mV}$ vs. $\mathrm{Ag} / \mathrm{AgCl}$ for increasing gallic acid concentrations (0.03 (1), 0.08 (2), 0.15 (3), 0.24 (4) and $\left.0.30 \mathrm{mmol} \mathrm{L}^{-1}(5)\right)$, and for five injections of a 10 times diluted white wine sample (Sample 1), and five injections of a 100 times diluted red wine sample (Sample 2) under flow injection analysis (FIA) conditions. Inset: calibration plot for gallic acid (b). Reprinted and adapted from [6] with permission. 
Barberis et al. performed the simultaneous amperometric detection of ascorbic acid (AA) and antioxidant capacity through the measurement of phenolic compounds in fruit juices using fullerenes- $\mathrm{C}_{60} / \mathrm{C}_{70}$ or nanotube-modified graphite sensor-biosensor systems, and ascorbate oxidase [10]. Results showed that the combination of fullerene and ascorbate oxidase resulted in the complete AA shielding and in the highest selecting capacity toward AA, while nanotubes only increased sensitivity without the ability to discriminate between the AA and the phenols contribution to the antioxidant capacity. These results led authors to hypothesize that fullerenes absorb more enzyme during dips, and can therefore oxidize more AA before it reaches the transducer surface. Although these biosensors systems were much cheaper compared with traditional methods, they are limited by the fragility of graphite rods and the laborious preparation protocol.

\section{Fullerenes in Affinity Biosensing}

The following subsections show as $\mathrm{C}_{60}$ and their derivatives have been used as electrode modifiers in the design of electrochemical affinity biosensors $[1,5,11,12,24,36-38]$, as well as nanocarriers $[15,17,19]$, and redox nanoprobes [15].

\subsection{Fullerenes as Electrode Modifiers in Affinity Biosensors}

Zhilei et al. [37] developed a label-free immunosensor for deoxynivalenol (DON) by covalent immobilization of the capture antibody on a GCE modified with a fullerene $\left(\mathrm{C}_{60}\right)$ /ferrocene $(\mathrm{Fc}) /$ ionic liquid composite film. The synergistic electrocatalytic activity of $\mathrm{C}_{60}$ and Fc remarkably enhanced the electron transfer while the biocompatibility of the ionic liquid (1,3-dibutylimidazolium bis(trifluoromethylsulfonyl) amine) improved the stability of the immobilized antibody. Electrochemical impedance spectroscopy provided a linear relationship between the electron transfer resistance, $\mathrm{R}_{\mathrm{et}}$, and DON concentration in the 0.001 to $0.3 \mathrm{ng} \mathrm{mL} \mathrm{L}^{-1}$ concentration range, and an LOD of $0.0003 \mathrm{ng} \mathrm{mL}^{-1}$. The immunosensor possessed an excellent 180 days storage stability and was successfully applied to the determination of DON in spiked food and biological samples. The same authors constructed a similar electrode platform using the ionic liquid 1-isobutyl-3-methylimidazolium bis(trifluoromethylsulfonyl)amine for the development of an impedimetric immunosensor for the determination of the herbicide paraquat [39]. The use of $\mathrm{C}_{60}$ and the ionic liquid led to 3.7 times enhanced sensitivity. The immunosensor exhibited also a great stability of more than 150 days, with a linear response from $3.89 \times 10^{-11}$ to $4.0 \times 10^{-8} \mathrm{~mol} \mathrm{~L}^{-1}$, an LOD of $9.0 \times 10^{-12} \mathrm{~mol} \mathrm{~L}^{-1}$, and allowed for the successful determination of paraquat in spiked and un-spiked meconium samples.

$\mathrm{Li}$ et al. [1] reported an amperometric sandwich-type immunosensor for the determination of heat-killed Escherichia coli (E. coli) O157:H7 using a $\mathrm{C}_{60}$-based biocompatible platform and enzyme functionalized $\mathrm{Pt}$ nanochains as tracing tags. The immunosensing platform involved a composite nano-layer of $\mathrm{C}_{60}, \mathrm{Fc}$ and thiolated chitosan (CHI-SH) with AuNP-coated $\mathrm{SiO}_{2}$ nanocomposites $\left(\mathrm{Au}-\mathrm{SiO}_{2}\right)$ assembled on the $\mathrm{CHI}-\mathrm{SH} / \mathrm{Fc} / \mathrm{C}_{60}$ composite. The biotinylated capture antibody (bio- $\left.\mathrm{Ab}_{1}\right)$ was immobilized after coating the $\mathrm{Au}-\mathrm{SiO}_{2}$ with avidin (see Figure 5a). $\mathrm{Au}-\mathrm{SiO}_{2}$ embedded $\mathrm{C}_{60} / \mathrm{Fc} / \mathrm{CHI}-\mathrm{SH}$ provided a biocompatible platform with increased surface area, allowing for the capture of a large amount of avidin and bio- $\mathrm{Ab}_{1}$. Glucose oxidase-functionalized Pt nanochains (PtNCs) were used as a tracing tag to label signal antibodies $\left(\mathrm{Ab}_{2}\right)$ (Figure $5 \mathrm{~b}$ ) for amplification purposes. The sandwich immunosensor allowed the detection of the target bacteria in the range of $3.2 \times 10^{1}$ to $3.2 \times 10^{6}$ colony forming units (CFUs) $\mathrm{mL}^{-1}$ range and an LOD of $15 \mathrm{CFU} \mathrm{mL}^{-1}$, which is far below the threshold established in clinical diagnosis. The applicability of this approach was demonstrated by the determination of E. coli in stool samples. 
(a)

Hexachloroplatinum(IV) Acid $\mathrm{H}_{2} \mathrm{PtCl}$
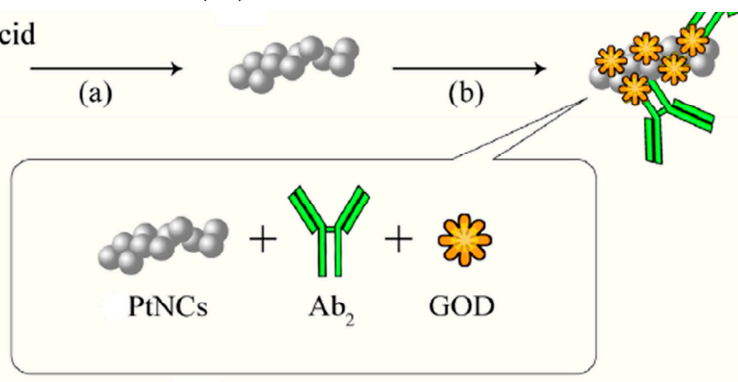

(b)

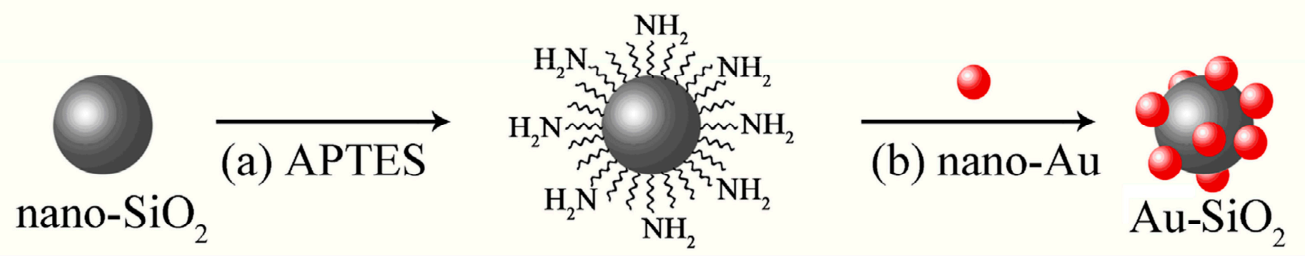

(c)
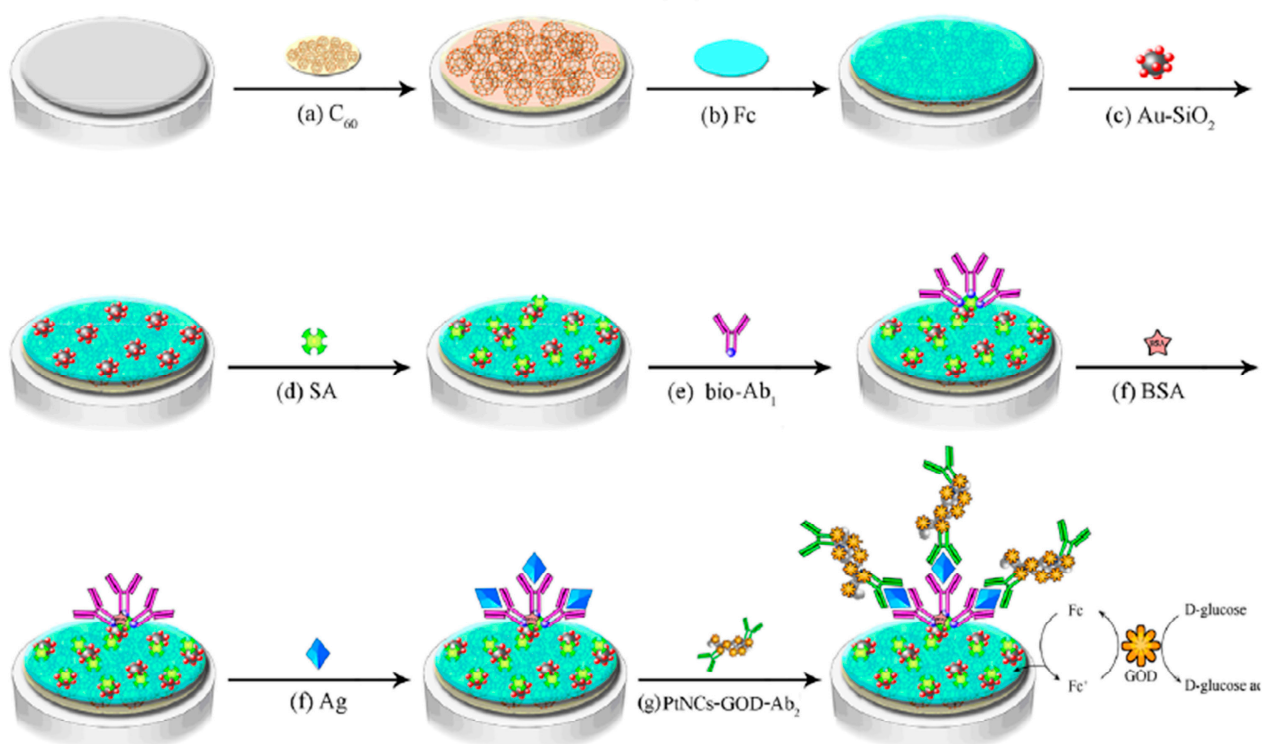

(d)
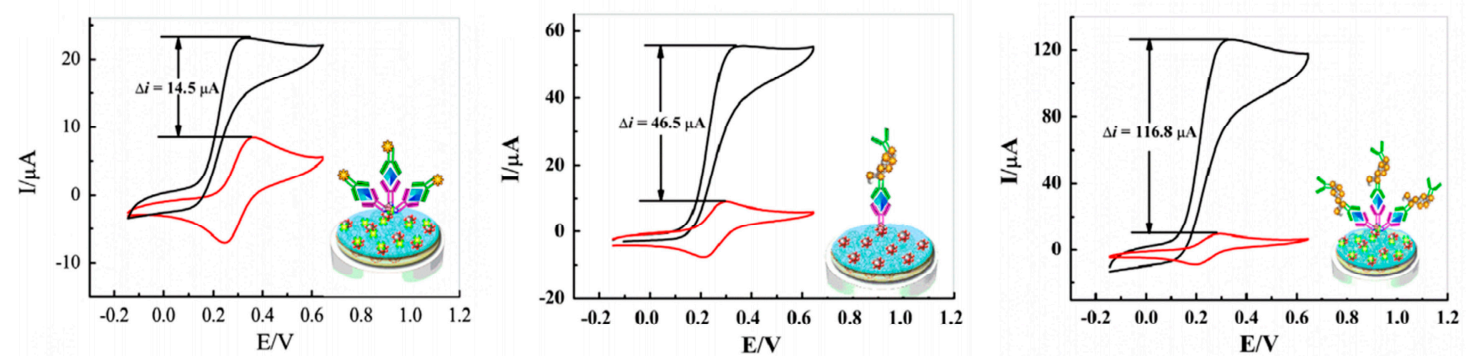

Figure 5. Scheme of the preparation of PtNCs-GOD-Ab 2 bioconjugates (a) and the AuNP-coated $\mathrm{SiO}_{2}$ nanocomposites $(\mathrm{Au}-\mathrm{SiO} 2)(\mathbf{b})$ and the fabrication of the electrochemical immunosensor and amplified detection (c); evaluation of the signal amplification effect of PtNCs and the biotin-avidin system (d). Reprinted and adapted from [1] with permission. 
A label-free electrochemical immunosensor was developed for determination of tumor necrosis factor $\alpha$ (TNF- $\alpha$ ) by using a nanocomposite containing fullerene-functionalized multiwalled CNTs and IL (1-butyl-3-methylimidazolium bis(trifluoromethyl sulfonyl)imide) $\left(\mathrm{C}_{60}-\mathrm{CNTs}-\mathrm{IL}\right)$ onto graphite SPEs (Figure 6) [12]. The capture antibody was covalently immobilized using ethyl carbodiimide/ N-hydroxysuccinimide (EDC/NHS) chemistry onto the activated carboxylic acid groups of the nanocomposite. The $\mathrm{C}_{60}$-CNTs-IL platform demonstrated the ability to act as an excellent electrocatalyst for oxidation of catechol used as a probe to monitor the immunorecognition event. The differential pulse voltammetric response decreased with the concentration of the target antigen with a dynamic range between 5.0 and $75 \mathrm{pg} \mathrm{mL}^{-1}$ and an LOD of $2.0 \mathrm{pg} \mathrm{mL}^{-1}$. The usefulness of this immunosensor was demonstrated by the analysis of spiked human serum samples.

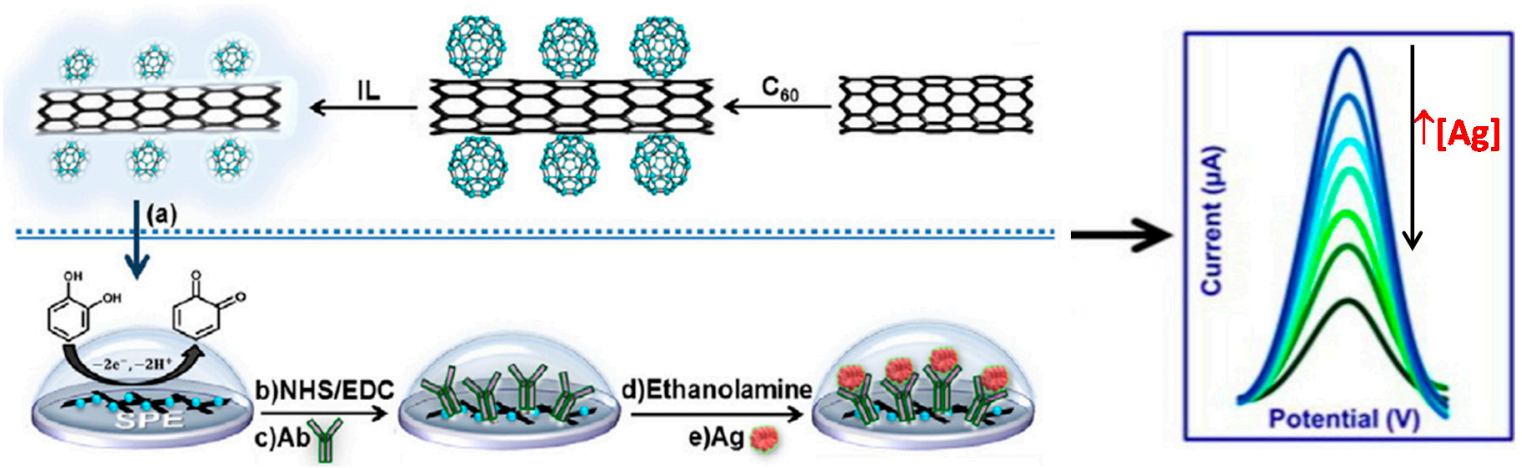

Figure 6. Schematic display of the electrochemical immunosensor for the determination of tumor necrosis factor $\alpha(\mathrm{TNF}-\alpha)$ at a $\mathrm{C}_{60}-\mathrm{CNTs}-\mathrm{IL}-$ modified screen-printed electrode (SPE), as well as differential pulse voltammetry (DPV) responses obtained with increasing concentrations of Ag (TNF- $\alpha$ ). Reprinted and adapted from [12] with permission.

An impedimetric immunosensor for the determination of the heat shock protein 70 (HSP70) was developed by EDC/NHS covalent immobilization of the capture antibody on a GCE modified with a fullerene $\mathrm{C}_{60}$ layer [11]. The immunosensor showed a linear increase in $\mathrm{R}_{\mathrm{ct}}$ with the HSP70 concentration in a range between 0.8 and $12.8 \mathrm{pg} \mathrm{mL}^{-1}$ and an LOD of $0.273 \mathrm{pg} \mathrm{mL}^{-1}$, as well as successful applicability to the analysis of real human blood serum samples. The wide linear range and easy preparation are the main features to highlight for this biosensor.

While it has been explored in less depth than in the preparation of electrochemical immunosensors, $\mathrm{C}_{60}$ and derivatives have also been employed to construct electrochemical DNA sensors.

A DNA-modified electrode for the electrochemical detection of the polymerase chain reaction (PCR) product of the 16S rDNA extracted from E. coli (JCM1649) was proposed by immobilizing a specific DNA probe onto a fullerene-impregnated SPE (FISPE) after activating the electrode with air plasma [36]. Results showed a dramatic improvement in the surface coverage of the immobilized probe DNA, as well as in the reduction peak current of the redox indicator $\left(\mathrm{Co}(\mathrm{phen}) 3^{3+}\right)$ measured by DPV due to the incorporation of fullerene. The developed DNA sensor allowed the clear detection of two base mismatches in the ca. 1500 bases-long target $16 \mathrm{~S}$ rDNA sequence.

Zhang et al. reported DNA sensors for the selective voltammetric determination of dopamine (DA) in the presence of AA by modifying a GCE with a complex of fullerene $\mathrm{C}_{60}$ nanotubes (FNTs) with a sequence-specific single-stranded (ss) DNA (FNT@DNA) physisorbed through a wrapping mechanism [24]. In these FNT@DNA complexes, the ssDNA chains were used as "surfactants" to render FNTs solubilized in water. The high selectivity towards DA detection against AA was attributed to the negative charge of the reduced modified electrode, which minimized the interference of negatively charged compounds and enhanced the determination of positively charged analytes in water due to electrostatic interaction. 
Gugoasa et al. compared the performance of biosensors prepared by immobilizing dsDNA physically on MWCNTs, synthetic monocrystalline diamond (DP) or fullerene- $\mathrm{C}_{60}$ pastes for the DPV sensing of three different neutransmitters: DA, epinenephrine, and norepinephrine [38]. Results showed that both the nature and the arrangement of carbon atoms in the carbon matrices had an important effect on the biosensors behavior. While larger signal enhancement for DA was obtained when dsDNA was immobilized on DP, wider dynamic concentration range and lower limit of detection were achieved by immobilization on MWCNT. The immobilization of dsDNA on fullerene- $\mathrm{C}_{60}$ paste provoked a decrease of both the LOD and the limit of quantification (LQ) values for DA determination compared with the immobilization onto DP and MWCNT pastes.

Gholivand et al. employed multivariate analysis to study the interaction mechanism of the carbidopa (CD) drug with double-stranded calf thymus DNA using a fullerene- $\mathrm{C}_{60}$-modified GCE by $\mathrm{CV}$, linear square voltammetry (LSV) and square wave voltammetry (SWV) [5]. Results demonstrated the interaction of $\mathrm{CD}$ with the minor groove of dsDNA, in agreement with the minor groove binding mode of small molecules, while fullerene- $\mathrm{C}_{60}$, as a larger molecule, recognized the major groove binding site of dsDNA. The oxidation of $\mathrm{CD}$ was adsorption controlled at the modified electrode and showed a significantly improved electrocatalytic behavior at $\mathrm{C}_{60} / \mathrm{GCE}$ compared with the bare GCE. Under optimized conditions, the decrease in the SWV responses corresponding to CD oxidation was linear with the dsDNA concentration between 0.1 and $25.0 \mathrm{nM}$. Moreover, the modified electrode exhibited an LOD of $0.03 \mathrm{nM}$, long-term stability, high sensitivity and feasibility to perform the determination of dsDNA in human serum samples.

\subsection{Fullerenes as Nanocarriers, Redox Nanoprobes and Signal Enhancers in Affinity Biosensors}

Han et al. [19] reported a supramolecular method using amino functionalized 3,4,9,10-perylenetetracarboxylic dianhydride $\left(\mathrm{PTC}-\mathrm{NH}_{2}\right)$ for the synthesis of amino and thiol groups-functionalized $\mathrm{C}_{60}$ nanoparticles $\left(\mathrm{FC}_{60} \mathrm{NPs}\right)$, which exhibited large surface active sites and good water solubility. The $\mathrm{FC}_{60} \mathrm{NPs}$ decorated with Prussian Blue-carried gold nanoparticles $\left(\mathrm{Au} @ \mathrm{~PB} / \mathrm{FC}_{60}\right)$ were subsequently used to attach detection aptamers and alkaline phosphatase (AP/AptII/Au@PB/FC 60 ), thus making it possible to use the nanoparticles as tracers in a sandwich aptasensor (Figure 7a). Moreover, onion-like mesoporous graphene sheets and AuNPs were used for this aptasensing platform because they allowed for the immobilization of a large amount of capture aptamers due to theirs porous structure and high surface-to-volume ratio, and provided a favorable microenvironment (Figure $7 \mathrm{~b}$ ). Using a dual signal amplification strategy by performing biocatalysis of AP towards ascorbic acid 2-phosphate (AA-P) for the in situ production of AA, followed by chemi-catalysis of $\mathrm{Au} @ \mathrm{~PB} / \mathrm{FC}_{60}$ towards $\mathrm{AA}$ to generate dehydroascorbic acid, which was detected by DPV, the aptasensor allowed the determination of platelet-derived growth factor B-chain (PBGF-BB) in a linear range between 0.002 and $40 \mathrm{nM}$ with an LOD of $0.6 \mathrm{pM}$. Therefore, the main contributions of this work include the large surface active sites and good water-stability offered by $\mathrm{FC}_{60} \mathrm{NPs}$, the high electrocatalytic activity of $\mathrm{Au} @ \mathrm{~PB} / \mathrm{FC}_{60}$, which greatly enhanced the detection signal, and the low background and favorable microenvironment of this nanomaterial, which makes it ideal for electrochemical biosensing applications. 
(A)
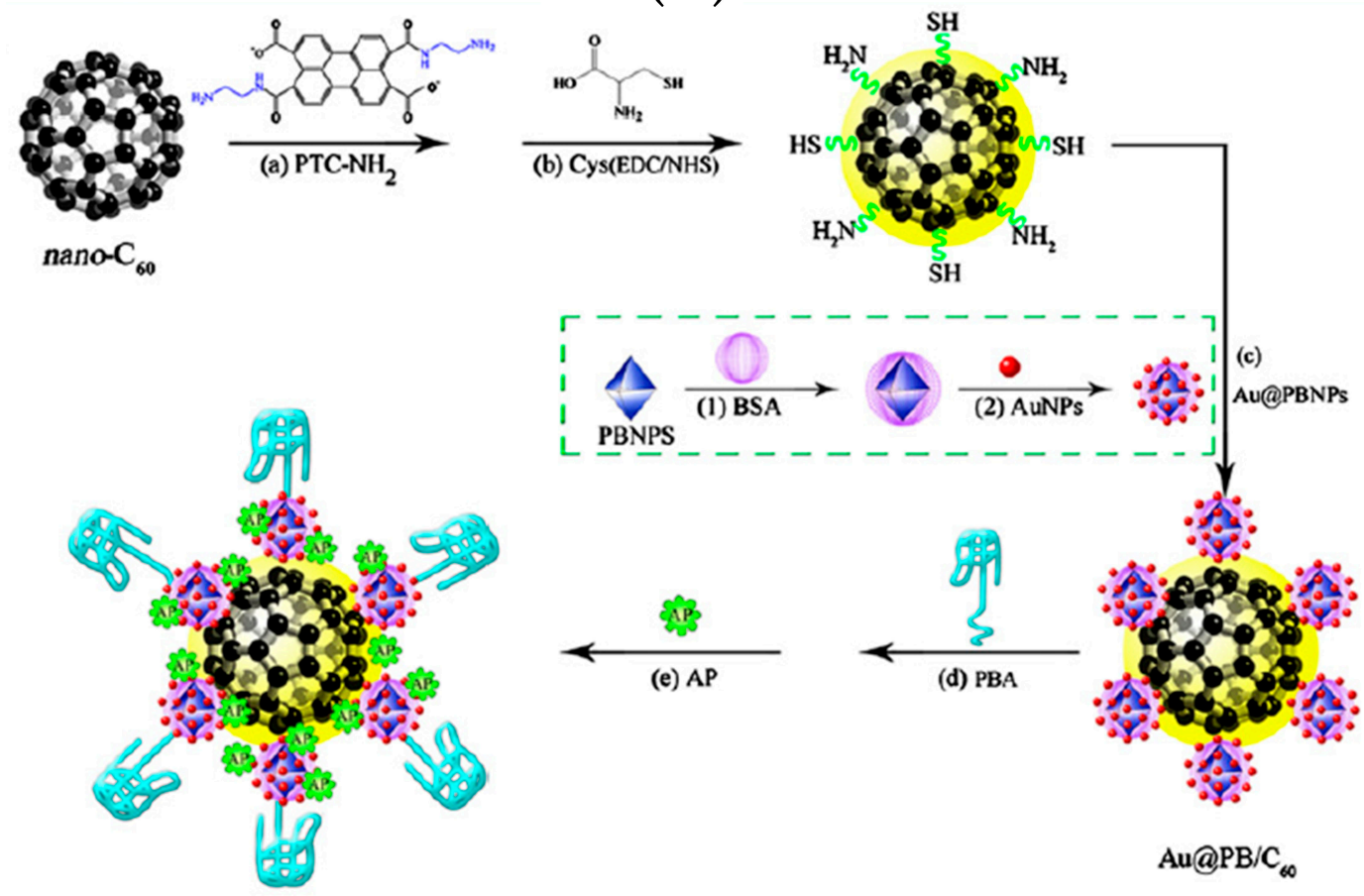

Apt II bioconjucates

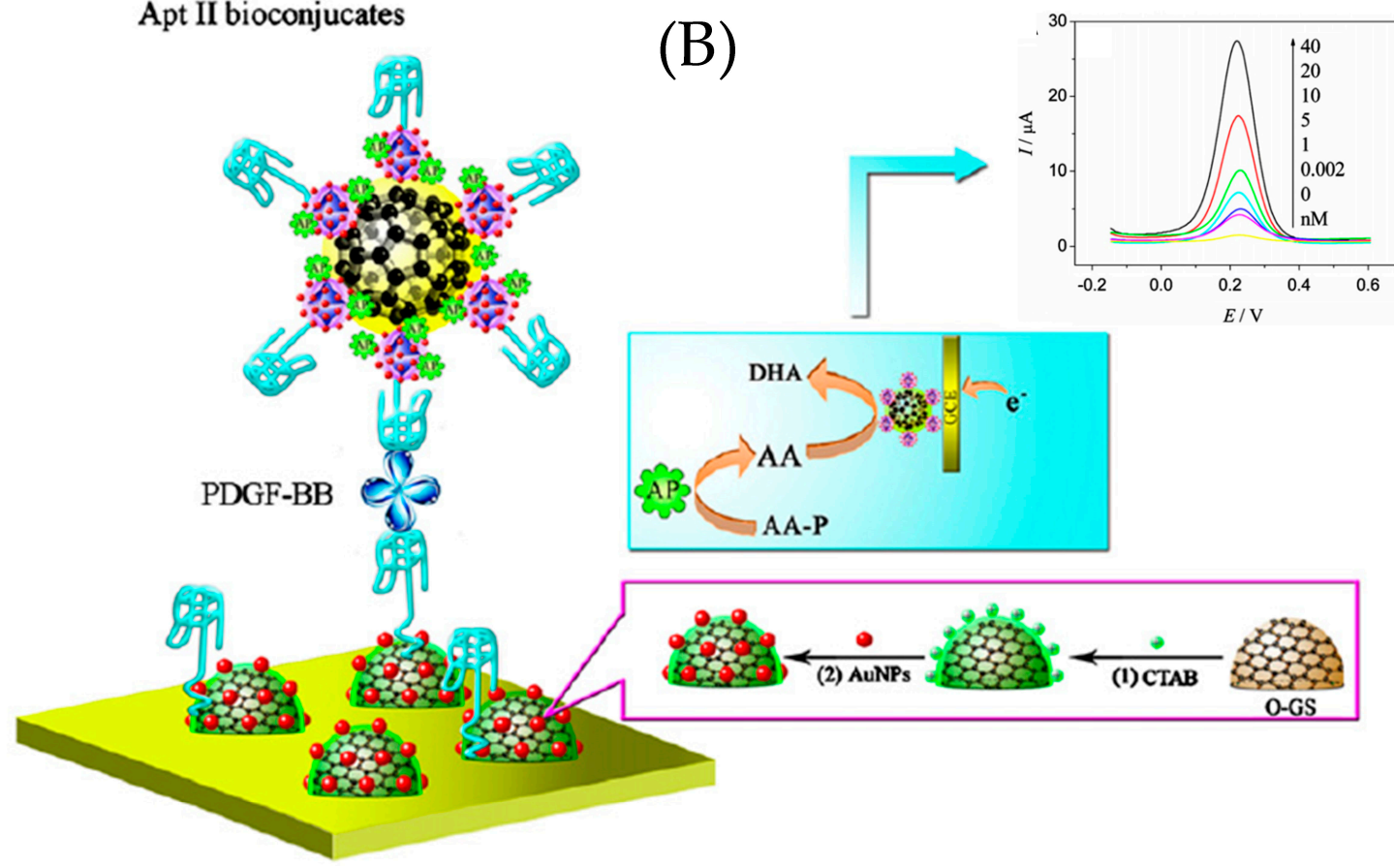

Figure 7. Schematic illustrations of the preparation of the AP/AptII/Au@PB/FC 60 aptasensing platform (A) and the stepwise aptasensor fabrication process including the diamond paste (DP) voltammograms recorded for increasing concentrations of platelet-derived growth factor B-chain (PDGF-BB) (B). Reprinted and adapted from [19] with permission.

The same authors [15] profited the inner redox activity of $\mathrm{C}_{60}$ to use $\mathrm{FC}_{60} \mathrm{NPs}$ as redox nanoprobes and nanocarriers to label detection antibodies $\left(\mathrm{Ab}_{2}\right)$ in a sandwich immunosensor designed for the determination of erythropoietin (EPO). In this approach, $\mathrm{C}_{60} \mathrm{NPs}$ were decorated with amino-terminated polyamidoamine (PAMAM) to provide NPs with better hydrophilicity and abundant 
amine groups for further modification. Subsequently, through amino-Au affinity reactions, AuNPs were immobilized on the PAMAM- $\mathrm{C}_{60} \mathrm{NPs}$ and the resulting Au-PAMAM- $\mathrm{C}_{60}$ NPs nanohybrid was used for the immobilization of the detector antibodies $\left(\mathrm{Ab}_{2}\right)$ (Figure 8). The immunosensing platform was fabricated by the effective and directional immobilization of capture antibodies $\left(A b_{1}\right)$ upon the attachment of protein A on Au nanodendrites (AuNDs)-decorated GCE. The electrochemical detection was performed by DPV after incubating the immunosensor with a drop of tetraoctylammonium bromide (TOAB), which acted as booster to arouse the inner redox activity of Au-PAMAM-C ${ }_{60}$ NPs. A linear calibration plot between the DPV oxidation peak current of the $\mathrm{Au}-\mathrm{PAMAM}-\mathrm{C}_{60} \mathrm{NPs}$ and the logarithmic values of EPO concentrations was found in the 0.01 to $80 \mathrm{mIU} \mathrm{mL}^{-1}$ range with an LOD of $0.0027 \mathrm{mIU} \mathrm{mL}^{-1}$. The as-prepared immunosensor was applied to the determination of EPO in human serum samples. It is important to note that this strategy opened a new avenue for exploring fullerenes as redox nanoprobes in the development of electrochemical biosensors.

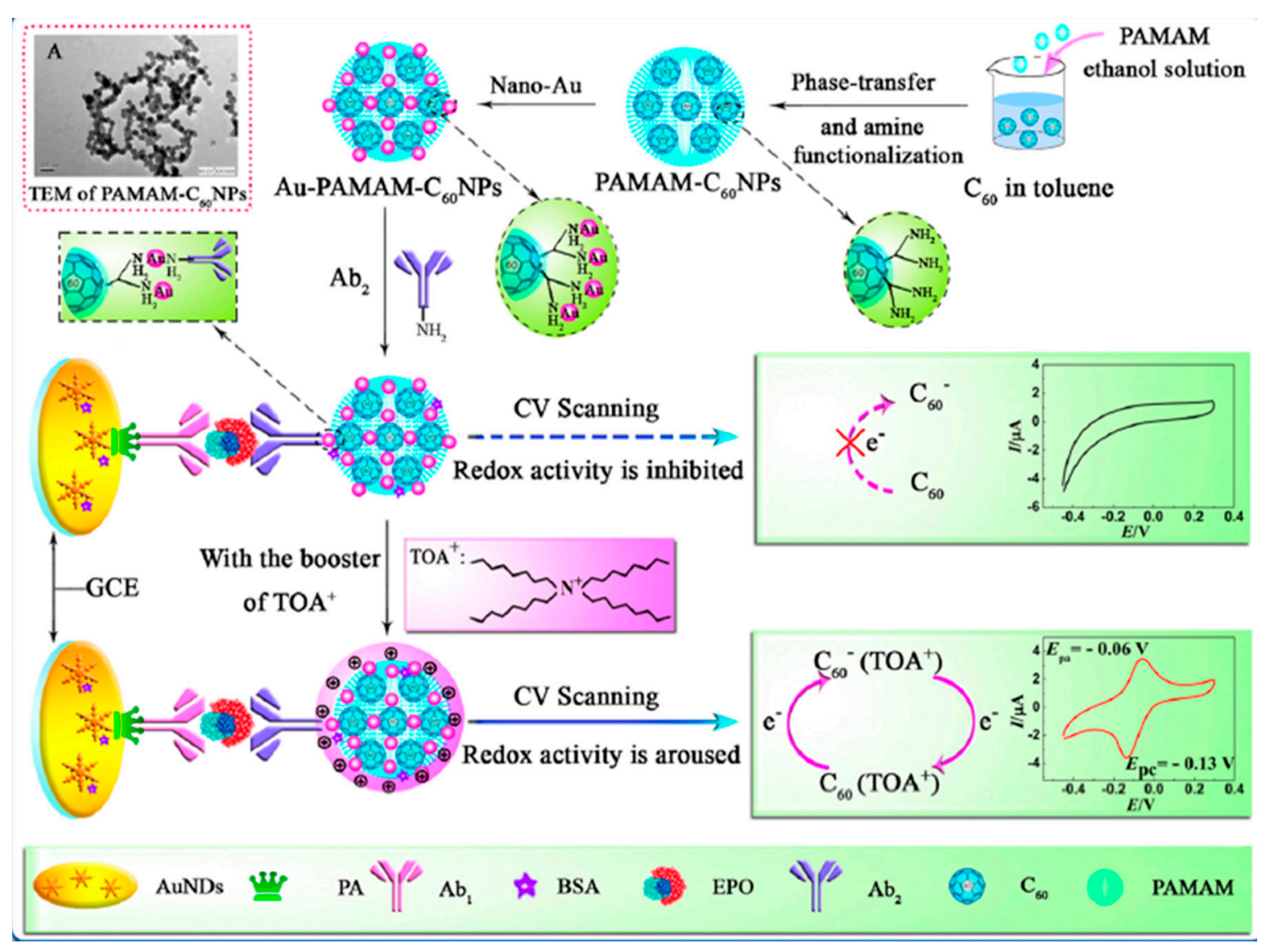

Figure 8. Schematic illustration of the synthesis of Au-PAMAM- ${ }_{60} \mathrm{NPs}$ used as nanotags in the preparation of an immunosensor for the determination of erythropoietin (EPO). The possible mechanism of the electrochemical reaction used to monitor the affinity reaction is also displayed. Reprinted from [15] with permission.

Wang et al. [17] reported a pseudo-bienzyme electrocatalytically amplified immunosensor for sensing the spore wall protein of Nosema bombycis (SWP N.b), a biomarker related with the Pebrine disease. In this immunosensor, $\mathrm{C}_{60} @ \mathrm{Pt}-\mathrm{Pd}$ nanoparticles were employed as efficient nanocarriers loaded with abundant hemin/G-quadruplex concatemers and antibodies, and L-Cysteine was used as the electrocatalytic substance to generate $\mathrm{H}_{2} \mathrm{O}_{2}$ in situ (Figure 9). The hemin/G-quadruplex concatemers supported on the $\mathrm{C}_{60} @ \mathrm{Pt}-\mathrm{Pd}$ nanoparticles served simultaneously as two kinds of catalyst and signal probe, thus saving the laborious process associated with labeling with enzymes and electron mediators. In the presence of L-Cysteine, the hemin/G-quadruplex first catalyzed the oxidation of 
L-Cysteine to L-Cystine, accompanied by an autocatalytic cycle generation of $\mathrm{H}_{2} \mathrm{O}_{2}$ under aerobic conditions and, afterwards, mimicking the catalytic activity of horseradish peroxidase (HRP), also quickly bioelectrocatalyzed the reduction of the produced $\mathrm{H}_{2} \mathrm{O}_{2}$ (Figure 9c). An increase in the DPV signals with the SWP N.b concentration was observed from 0.001 to $100 \mathrm{ng} \mathrm{mL}^{-1}$ with an LOD of $0.56 \mathrm{pg} \mathrm{mL}^{-1}$, which is $\sim 450$ times lower than that provided by the Enzyme-Linked ImmunoSorbent Assay (ELISA) methodology. This high sensitivity was attributed to the excellent loading capacity of the $\mathrm{C}_{60} @ \mathrm{Pt}-\mathrm{Pd}$ nanoparticles and the superior electrocatalytic performance of the hemin/G-quadruplex DNAzymes. Preliminary results using normal silkworm blood spiked with SWP N.b demonstrated the promising applicability of this approach.
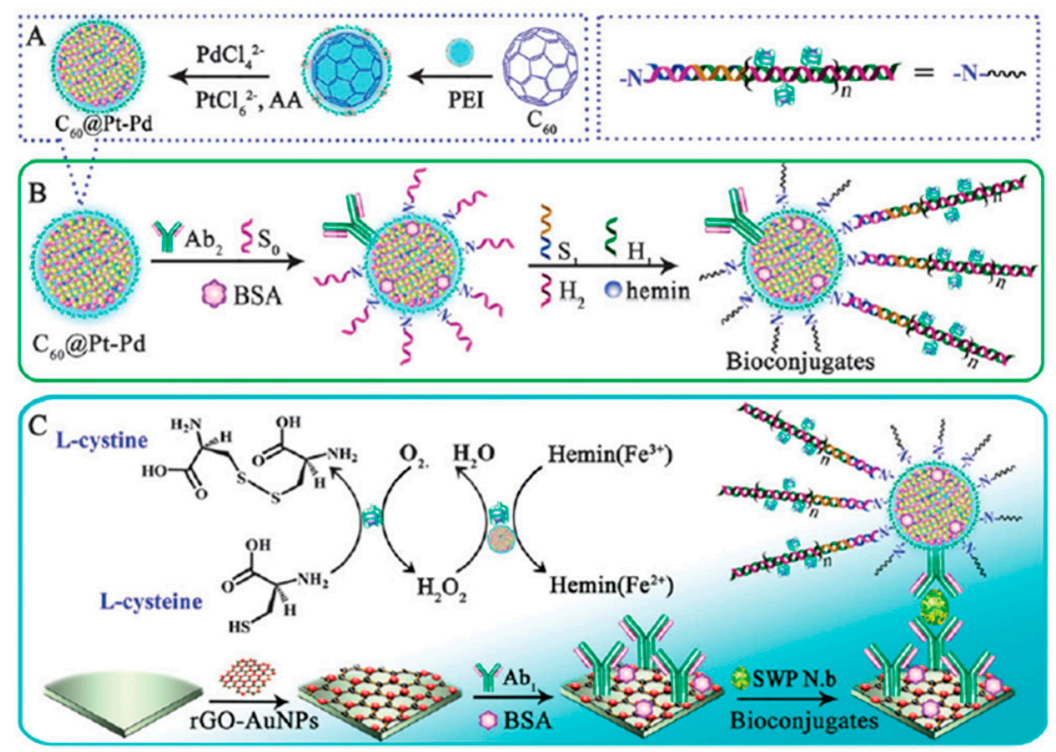

Figure 9. Schematic display of the stepwise assembly procedure of an immunosensor for the determination of the spore wall protein of Nosema bombycis (SWP N.b) biomarker using $\mathrm{C}_{60} @ \mathrm{Pt}-\mathrm{Pd}$ nanoparticles as nanocarriers. The electrochemical detection fundamentals is also displayed. Reprinted from [17] with permission.

\section{General Conclusions, Main Challenges and Future Directions}

Nanostructured materials have been significantly used in recent years to create a new generation of electrochemical biosensors with improved analytical performance, miniaturization ability, and reduced response time, which are features of great interest in fields such as clinical diagnosis. Among different nanomaterials, carbon nanomaterials and particularly fullerene- $\mathrm{C}_{60}$ and some of their derivatives ( $\mathrm{FC}_{60} \mathrm{NPs}$ and FNTs) have been shown to hold potential promise for this purpose due to their unique electrochemical and physicochemical properties, together with biocompatibility characteristics.

This article gives an overview of the key aspects of the electrochemical biosensors reported so far involving the use of fullerenes and derivatives as electrode modifiers, nanocarriers and redox nanoprobes, and in connection to various kinds of biomolecules (enzymes, antibodies and oligonucleotides). The prospects of effectively modifying fullerene-based nanomaterials to ramp up the sensitivity and functionality of the resulting biodevices are also discussed together with challenges to be faced and future directions.

Results reported in this field demonstrate that electrodes modified with partially reduced fullerene- $\mathrm{C}_{60}$ show exceptional properties such as large electroactive surface area able to immobilize large amounts of bioreceptors, the promotion of the biomolecules electrochemistry, excellent electronic conductivity, and good biocompatibility [4]. From the discussed works, it is deduced that fullerene- $\mathrm{C}_{60}$ and derivatives not only provide a suitable immobilization platform for DNA and antibodies, but have 
also the ability to induce a proper orientation in redox-active proteins, allowing for the direct electron transfer of enzymes and other proteins such as cyt c [35], GOx [13,31], Hb [18] and laccase [6,33]. Fullerene nanomaterials can act also as efficient nanocarriers due to the high surface area and good biocompatibility in the preparation of electrochemical biosensors with enhanced sensitivity [17]. Moreover, these materials have been used as redox nanoprobes to prepare electrochemical affinity biosensors through the synthesis of hydrophilic $\mathrm{C}_{60}$-based nanomaterials and exploiting the inner redox activity of $C_{60}$ [15]. While $C_{60}$ and derivatives have been used as electrode modifiers in catalytic biosensors, in electrochemical affinity biosensors they have been employed as electrode modifiers [1,5,6,9-13,18,24,31-38], nanocarriers [15,17,19] and redox nanoprobes [15]. Although most of the work has been done in developing catalytic biosensors and immunosensors, there is no doubt that fullerenes can be used as an active material in biosensing devices for the determination of biomolecules of a genetic nature. Indeed, the illustrative examples selected clearly show that electrochemical biosensors involving fullerene nanomaterials can be designed for the determination of a wide variety of target analytes such as glucose, $\mathrm{H}_{2} \mathrm{O}_{2}$, poplyphenols and AA, neurotransmitters such as DA, epinenephrine and norepinephrine, mycotoxins (DON), proteins (TNF- $\alpha$, HSP70, PBGF-BB, EPO and SWP N.b), bacteria (E. coli) and oligonucleotides (dsDNA).

However, despite the great progress that has occurred in recent years and the bright prospects for this field, the function of fullerenes is still under investigation. In fact, in order to exploit their potentiality to the fullest, it is essential to discover promising advantages of their use in the construction of biosensing devices other than enhancing the electron transfer rate. Another major issue that requires attention is the examination of how conveniently this nanomaterial can be incorporated into a biosensor and how robustly it can deliver its performance under different experimental conditions to detect and measure different types of biomolecules, in comparison to biosensors prepared so far with other nanomaterials for similar purposes. Although the lack of systematic comparative studies of fullereneand other nanomaterials-based electrochemical biosensing devices does not allow us to discuss this aspect exhaustively, in general the popularity $\mathrm{C}_{60}$ has somewhat diminished in recent years with the rise of CNTs and graphene, more scalable and practical carbon nanomaterials. However, the uniform size and shape as well as its availability for chemical modification makes $\mathrm{C}_{60}$ widely used at this time for other types of applications such as therapeutic purposes taking advantage of its anti-human immunodeficiency virus (HIV) activity by targeting important HIV enzymes [40].

Although biosensors constructed with fullerene offer high sensitivity, selectivity and good reproducibility for electrochemical biosensing, the cost of this nanomaterial and of the agents and tools required for its functionalization is an important limitation to be considered for their application in point-of-care (POC) diagnosis where cost-effective and easy-to-handle configuration are demanded. However, it is expected that the advantages already demonstrated and those that may arise in future research will compensate for these limitations. Fullerene-based biosensors may achieve the wide acceptance of other nanomaterials-based biosensors and play an important role also in POC diagnosis. A mandatory prior step to this stage is to demonstrate the robustness and convenient behavior of the fullerene-involved biosensors in challenging biological samples and not just in buffered solutions and doped clinical samples, as occurred in most of the reported works. Another major challenge requiring proper attention is to explore the possibilities for multiplexing. It is striking that given the current growing interest in performing multidetermination, to date there is not any electrochemical biosensor using fullerenes used for the determination of more than one analyte. Moreover, the range of applications is still limited, and further investigation in new functionalization routes, together with the exploration of other fullerene- $\mathrm{C}_{60}$ analogues for the construction of electrochemical biosensors, is envisaged to expand the range of applications as well as to improve their performance in terms of sensitivity and stability. On the other hand, due to the biocompatibility of fullerene- $\mathrm{C}_{60}$ and derivatives, additional works should be also focused on functionalization with other types of bioreceptors such as microorganisms, cells or their organelles. The integration of the fullerene-involved biosensors in automated and miniaturized systems to achieve electrochemical POC systems is another key challenge. 
In summary, despite the further efforts required to address these important issues, the rapid development and attention in the research of functionalizing fullerene and cutting-edge biosensor technology over the past few years emphasizes the possibility that, in the near future, fullerene-based biosensors will appear as effective devices in electrochemical biosensing and be applicable commercially for POC diagnosis.

Acknowledgments: The financial support of the CTQ2015-70023-R and CTQ2015-64402-C2-1-R (Spanish Ministerio de Economía y Competitividad Research Projects) and S2013/MT3029 (NANOAVANSENS Program from the Comunidad de Madrid) are gratefully acknowledged.

Conflicts of Interest: The authors declare no conflict of interest.

\section{References}

1. Li, Y.; Fang, L.; Cheng, P.; Deng, J.; Jiang, L.; Huang, H.; Zheng, J. An electrochemical immunosensor for sensitive detection of Escherichia coli O157:H7 using $\mathrm{C}_{60}$ based biocompatible platform and enzyme functionalized Pt nanochains tracing tag. Biosens. Bioelectron. 2013, 49, 485-491. [CrossRef] [PubMed]

2. Kato, D.; Niwa, O. Carbon-based electrode materials for DNA electroanalysis. Anal. Sci. 2013, $29,385-392$. [CrossRef] [PubMed]

3. Săndulescu, R.; Tertiş, M.; Cristea, C.; Bodoki, E. New materials for the construction of electrochemical biosensors. In Biosensors-Micro and Nanoscale Applications; Rinken, T., Ed.; InTech: Rijeka, Croatia, 2015.

4. Pilehvar, S.; de Wael, K. Recent advances in electrochemical biosensors based on fullerene- $\mathrm{C}_{60}$ nano-structured platforms. Biosensors 2015, 5, 712-735. [CrossRef] [PubMed]

5. Gholivand, M.B.; Jalalvand, A.R.; Goicoechea, H.C. Multivariate analysis for resolving interactions of carbidopa withdsDNA at a fullerene-C60/GCE. Int. J. Biol. Macromol. 2014, 69, 369-381. [CrossRef] [PubMed]

6. Lanzellotto, C.; Favero, G.; Antonelli, M.L.; Tortolini, C.; Cannistraro, S.; Coppari, E.; Mazzei, F. Nanostructured enzymatic biosensor based on fullerene and gold nanoparticles: Preparation, characterization and analytical applications. Biosens. Bioelectron. 2014, 55, 430-437. [CrossRef] [PubMed]

7. López, A.M.; Mateo-Alonso, A.; Prato, M. Materials chemistry of fullerene $\mathrm{C}_{60}$ derivatives. J. Mater. Chem. 2011, 21, 1305-1318.

8. Sherigara, B.S.; Kutner, W.; D'Souza, F. Electrocatalytic properties and sensor applications of fullerenes and carbon nanotubes. Electroanalysis 2003, 15, 753-772. [CrossRef]

9. Saeedfar, K.; Heng, L.Y.; Ling, T.L.; Rezayi, M. Potentiometric urea biosensor based on an immobilised fullerene-urease bio-conjugate. Sensors 2013, 13, 16851-16866. [CrossRef] [PubMed]

10. Barberis, A.; Spissu, Y.; Fadda, A.; Azara, E.; Bazzu, G.; Marceddu, S.; Angioni, A.; Sanna, D.; Schirra, M.; Serra, P.A. Simultaneous amperometric detection of ascorbic acid and antioxidant capacity in orange, blueberry and kiwi juice, by a telemetric system coupled with a fullerene-or nanotubes-modified ascorbate subtractive biosensor. Biosens. Bioelectron. 2015, 67, 214-223. [CrossRef] [PubMed]

11. Demirbakan, B.; Sezgintürk, M.K. A novel immunosensor based on fullerene $C_{60}$ for electrochemical analysis of heat shock protein 70. J. Electroanal. Chem. 2016, 783, 201-207. [CrossRef]

12. Mazloum-Ardakani, M.; Hosseinzadeh, L.; Khoshroo, A. Label-free electrochemical immunosensor for detection of tumor necrosis factor $\alpha$ based on fullerene-functionalized carbon nanotubes/ionic liquid. J. Electroanal. Chem. 2015, 757, 58-64. [CrossRef]

13. Zhilei, W.; Zaijun, L.; Xiulan, S.; Yinjun, F.; Junkang, L. Synergistic contributions of fullerene, ferrocene, chitosan and ionic liquid towards improved performance for a glucose sensor. Biosens. Bioelectron. 2010, 25, 1434-1438. [CrossRef] [PubMed]

14. Guldi, D.M.; Rahman, G.M.A.; Sgobba, V.; Ehli, C. Multifunctional molecular carbon materials-From fullerenes to carbon nanotubes. Chem. Soc. Rev. 2006, 35, 471-487. [CrossRef] [PubMed]

15. Han, J.; Zhuo, Y.; Chai, Y.Q.; Xiang, Y.; Yuan, R. New type of redox nanoprobe: $\mathrm{C}_{60}$-based nanomaterial and its application in electrochemical immunoassay for doping detection. Anal. Chem. 2015, 87, 1669-1675. [CrossRef] [PubMed] 
16. Wang, H.; Bai, L.; Chai, Y.; Yuan, R. Synthesis of multi-fullerenes encapsulated palladium nanocage, and its application in electrochemiluminescence immunosensors for the detection of Streptococcus suis serotype 2. Small 2014, 10, 1857-1865. [CrossRef] [PubMed]

17. Wang, Q.; Song, Y.; Xie, H.; Chai, Y.; Yuan, Y.; Yuan, R. L-Cysteine induced hemin/G-quadruplex concatemers electrocatalytic amplification with $\mathrm{Pt}-\mathrm{Pd}$ supported on fullerene as a nanocarrier for sensing the spore wall protein of Nosema bombycis. Chem. Commun. 2015, 51, 1255-1258. [CrossRef] [PubMed]

18. Sheng, Q.; Liu, R.; Zheng, J. Fullerene-nitrogen doped carbon nanotubes for the direct electrochemistry of hemoglobin and its application in biosensing. Bioelectrochemistry 2013, 94, 39-46. [CrossRef] [PubMed]

19. Han, J.; Zhuo, Y.; Chai, Y.Q.; Yuan, R.; Xiang, Y.; Zhu, Q.; Liao, N. Multi-labeled functionalized $\mathrm{C}_{60}$ nanohybrid as tracing tag for ultrasensitive electrochemical aptasensing. Biosens. Bioelectron. 2013, 46, 74-79. [CrossRef] [PubMed]

20. Salvati, E.; Stellacci, F.; Krol, S. Nanosensors for early cancer detection and for therapeutic drug monitoring. Nanomedicine 2015, 10, 3495-3512. [CrossRef] [PubMed]

21. Afreen, S.; Muthoosamy, K.; Manickam, S.; Hashim, U. Functionalized fullerene $\left(\mathrm{C}_{60}\right)$ as a potential nanomediator in the fabrication of highly sensitive biosensors. Biosens. Bioelectron. 2015, 63, 354-364. [CrossRef] [PubMed]

22. Goyal, R.N.; Gupta, V.K.; Bachheti, N. Fullerene-C 60 -modified electrode as a sensitive voltammetric sensor for detection of nandrolone-An anabolic steroid used in doping. Anal. Chim. Acta 2007, 597, 82-89. [CrossRef] [PubMed]

23. Goyal, R.N.; Gupta, V.K.; Bachheti, N.; Sharma, R.A. Electrochemical sensor for the determination of dopamine in presence of high concentration of ascorbic acid using a fullerene- $\mathrm{C}_{60}$ coated gold electrode. Electroanalysis 2008, 20, 757-764. [CrossRef]

24. Zhang, X.; Qu, Y.; Piao, G.; Zhao, J.; Jiao, K. Reduced working electrode based on fullerene $\mathrm{C}_{60}$ nanotubes@DNA: Characterization and application. Mat. Sci. Eng. B 2010, 175, 159-163. [CrossRef]

25. Kachoosangi, R.T.; Banks, C.E.; Compton, R.G. Graphite impurities cause the observed electrocatalysis seen at $\mathrm{C}_{60}$ modified glassy carbon electrodes in respect of the oxidation of L-Cysteine. Anal. Chim. Acta 2006, 566, 1-4. [CrossRef]

26. Griese, S.; Kampouris, D.K.; Kadara, R.O.; Banks, C.E. Misinterpretations of the electro-catalysis observed at $\mathrm{C}_{60}$ modified glassy carbon electrodes for the determination of atenolol. Electrochem. Commun. 2008, 10, 1633-1635. [CrossRef]

27. Griese, S.; Kampouris, D.K.; Kadara, R.O.; Banks, C.E. A critical review of the electrocatalysis reported at $\mathrm{C}_{60}$ modified electrodes. Electroanalysis 2008, 20, 1507-1512. [CrossRef]

28. Griese, S.; Kampouris, D.K.; Kadara, R.O.; Banks, C.E. The underlying electrode causes the reported "electrocatalysis" observed at $\mathrm{C}_{60}$-modified glassy carbon electrodes in the case of N-(4-hydroxyphenyl)ethanamide and salbutamol. Electrochim. Acta 2008, 53, 5885-5890. [CrossRef]

29. Xiao, L.; Wildgoose, G.G.; Crossley, A.; Compton, R.G. The electroreduction of " $\mathrm{C}_{60}$ " films inaqueous electrolyte does not lead to alkalimetal ion insertion-Evidence for the involvement of adventitious poly-epoxidated $\mathrm{C}_{60}\left(\mathrm{C}_{60} \mathrm{O}_{n}\right)$. Sens. Actuators B Chem. 2009, 138, 397-401. [CrossRef]

30. Xiao, L.; Wildgoose, G.G.; Compton, R.G. Exploring the origins of the apparent "electrocatalysis" observed at $\mathrm{C}_{60}$ film-modified electrodes. Sens. Actuators B Chem. 2009, 138, 524-531. [CrossRef]

31. Gao, Y.F.; Yang, T.; Yang, X.L.; Zhang, Y.S.; Xiao, B.L.; Hong, J.; Sheibani, N.; Ghourchian, H.; Hong, T.; Moosavi-Movahedi, A.A. Direct electrochemistry of glucose oxidase and glucose biosensing on a hydroxyl fullerenes modified glassy carbon electrode. Biosens. Bioelectron. 2014, 60, 30-34. [CrossRef] [PubMed]

32. Lin, L.H.; Shih, J.S. Immobilized fullerene $\mathrm{C}_{60}$-enzyme-based electrochemical glucose sensor. J. Chin. Chem. Soc. 2011, 58, 228-235. [CrossRef]

33. Tortolini, C.; Sanzò, G.; Antiochia, R.; Mazzei, F.; Favero, G. Application of a nanostructured enzymatic biosensor based on fullerene and gold nanoparticles to polyphenol detection. In Biosensors and Biodetection: Methods and Protocols; Prickril, B., Rasooly, A., Eds.; Humana Press: Clifton, NJ, USA, 2017; p. 41.

34. Csiszár, M.; Szû́cs, Á.; Tölgyesi, M.; Mechler, Á.; Nagy, J.B.; Novák, M. Electrochemical reactions of cytochrome $c$ on electrodes modified by fullerene films. J. Electroanal. Chem. 2001, 497, 69-74. [CrossRef]

35. D'Souza, F.; Rogers, L.M.; O’Dell, E.S.; Kochman, A.; Kutner, W. Immobilization and electrochemical redox behavior of cytochrome $c$ on fullerene film-modified electrodes. Bioelectrochemistry 2005, 66, 35-40. [CrossRef] [PubMed] 
36. Shiraishi, H.; Itoh, T.; Hayashi, H.; Takagi, K.; Sakane, M.; Mori, T.; Wang, J. Electrochemical detection of $E$. coli 16S rDNA sequence using air-plasma-activated fullerene-impregnated screen printed electrodes. Bioelectrochemistry 2007, 70, 481-487. [CrossRef] [PubMed]

37. Zhilei, W.; Xiulan, S.; Zaijun, L.; Yinjun, F.; Guoxiao, R.; Yaru, H.; Junkang, L. Highly sensitive deoxynivalenol immunosensor based on a glassy carbon electrode modified with a fullerene/ferrocene/ionic liquid composite. Microchim. Acta 2011, 172, 365-371. [CrossRef]

38. Gugoasa, L.A.; Stefan-van Staden, R.I.; Ciucu, A.A.; van Staden, J.F. Influence of physical immobilization of dsDNA on carbon based matrices of electrochemical sensors. Curr. Pharm. Anal. 2014, 10, 20-29. [CrossRef]

39. Xiulan, S.; Zaijun, L.; Yan, C.; Zhilei, W.; Yinjun, F.; Guoxiao, R.; Yaru, H. Electrochemical impedance spectroscopy for analytical determination of paraquat in meconium samples using an immunosensor modified with fullerene, ferrocene and ionic liquid. Electrochim. Acta 2011, 56, 1117-1122.

40. Cha, C.; Shin, S.R.; Nasim, A.; Dokmeci, M.R.; Khademhosseini, A. Carbon-based nanomaterials: Multifunctional Materials for Biomedical Engineering. ACS Nano 2013, 7, 2891-2897. [CrossRef] [PubMed]

(C) 2017 by the authors. Licensee MDPI, Basel, Switzerland. This article is an open access article distributed under the terms and conditions of the Creative Commons Attribution (CC BY) license (http:/ / creativecommons.org/licenses/by/4.0/). 